\title{
Discussion on Reform of Practice Model for Higher Education
}

\author{
Wang Rongbo,Feng Qiang \\ College of Mathematics and Computer Science,Yan'an University,Yan'an 716000,China \\ yadxwrb76@163.com
}

\begin{abstract}
The practice and training was taken in a very important position in the in the higher education system. According to the defects of the practice model in current higher education, and combining with the situation of poor adaptability in career for the college graduates, some suggestions and considerations for the reform of practice model were proposed with the trend of the education reform. Firstly, the practice model of higher education were researched and explored, and the advantages and disadvantages of each practice model were presented concretely, the survived problems of the current practice model were summarized. According to the direction of constructing the concept of the new education practice model, cultivation of comprehensive high- quality talents and development of scientific practice model system, some proposals and suggestions of reform were proposed creatively. The analysis and discussion of the practice model is profound and practical, the suggestions which proposed in this paper is concrete and effective, these results will provide effective and meaningful value in the process of the practice model reform of higher education in the future.
\end{abstract}

Keywords- higher education, practice model, reform, suggestion

Class number: $G 646$

\section{I.INTRODUCTION}

The practice is the important and necessary phase in the higher education for every major, it is a good and effective test and reflection of application and manipulative ability for the students, and also it is a norm and standard with testing of the practice ability of the undergraduates. The practice also can cultivate the spirit of loving the career and cherishing the occupations, cultivate the responsibility and enterprise for the students. With the lasting expansion of the university, and the process of educational reform deeply, especially when confronting to the severe situation of great employment pressure, the reform of educational practice model should be researched and discussed necessarily and urgently.

In China, the practice phase just is considered as the secondary and assistant subject, which is seemed like be survived but is hollow. Eventually, the phenomena that a graduate from Electronic and Information Engineering major cannot use the universal meter, a graduate form computer major can't install the computer and install the operating system. It is really that the student with high scores but low abilities, or just because the education system is a castle in the air without a good solid foundation. The cultivation of the practice abilities is lacked.
Presently, besides the medical major is demanded of one year clinical practice experience in China, for the other majors, the credits of practice are very less in many colleges, always, the practices are developed in the centralized and limited time in the summer vacation, and the test requirements is low, generally speaking, everybody can pass the practice test and get the credits. And the so-called social practice in vacation mostly just a formality. It just need a practice report and without any really essential things. Eventually, it results in the strange and uncoordinated phenomenon that the employment rate of the graduates is lower than the vocational students in China.

According to this phenomenon and problem, many universities are trying to reform of the education system, and some colleges have explored a successful way. Taking the Yiwu Industrial and Commercial College in China, as an example, as the CCTV news reported. And obviously, one model cannot solve all the problems, but the experiment and reform which is taken by the vice-president JIA Shaohua in Yiwu Industrial and Commercial College has provided a possible for the better or for the worse. This is the reform of the practice model, and also the reform of educational system ${ }^{[1]}$.

According to the defects of the practice model in current higher education, and combining with the situation of poor adaptability in career for the college graduates, some suggestions and considerations for the reform of practice model are going to be proposed in this paper with the trend of the education reform. Maybe the suggestions are provided as the meaningful reference in the reform application.

\section{II.DISCUSSION ON THE PRACTICE MODEL OF HIGHER EDUCATION}

The quality of the higher education is developed rapidly in China, and the reform is raged like a storm, especially in recent 10 years, according to the summary of the practice and reform of the education in China, the educational practice model can be concluded as follows:

(1) Model of embedding in the courses. In this model, the content of the practice is essential and fundamental relatively, combining with the curriculum in the classroom, especially, in the fundamental education phases such as freshmen and sophomores, some short-term practices such as Electronic Practice, metalworking experience, software design practice, etc. are arranged for assimilating the courses contents, these practices always are completed in on short term. In this practice model, the students do the practices under the guidance of the teacher based on the fundamental knowledge reached in and out of the lessons. 
The practice contents are changed according to the change of courses with diversification of varieties and low risks, students can master and assimilate the skills and practice contents easily. On the other side, the drawback is that the depth is not enough, and the abilities of application skills which the student mastered are very limited.

(2) Fixed-pointed and centralized management model. This model is mainly fitted to the upperclassman, especially in the medical colleges and teaching colleges, the application of practices in this model is very normal, and it is tending to normalization and regularization in theses colleges which demanding high specialty. And as well as in the higher vocational school, it is very universal. In this practice model, the colleges always have the fixed-pointed enterprises and practice base. The practice time is due to the unified arrangements by the colleges during the summer vacation. The fixed-pointed and centralized management practice model is showed with system and large scale, the practice time is long relatively, and it plays a very key and important role in improving the specialized skill, expanding the specialized horizons, and exercising the practice ability.

(3) Composite formation model. In this practice model, the student coming from different of subjects and majors are composited and organized together by the colleges, a practice formation is formed and all the students involves the practice together in a certain time and on a certain position. In this complicated model, the strong organization ability and the coordination ability are required for the guidance teachers and organizers. It demands the teacher is equipped with abroad accumulation of knowledge. The contents of these practices are showed in involving some social practice activities and some social management activities, the students benefit the team cooperation consciousness and cooperation spirit from the teams and organization. In this model, the students generally have much interesting in the practice, and the effect and result is very nice.

(4) Mock scene model. There are some mock scene practice examples such as the mock United Nations Conference in Northwest poly-technical university in China, and moot court of political science and law university, mock classroom and lesson of teaching university, and some various debate competitions, robot design competitions etc. through these mock scenes and practices, the practical application ability and strain capacity are cultivated and improved. But this form of practice model only confront to limited brave and outstanding students and without universality. Many ordinary students don't want to, don't dare to, and don't able to challenge themselves. Then, they will not have the chance to participate in the practices and activities.

In addition, there are some other practice models such as partial consignation practice model, scattering back hometown practice model and so on. In short, although there are many kinds of practice model, the effect should be tested and evaluated by the society. The final end-result and a stay-dot is promotion of the education development and modernization, and for the cultivation and improvement of the practice capability and innovation ability of the people $\mathrm{e}^{[2-3]}$.

\section{III.MAIN PROBLEMS OF PRACTICE MODEL IN CURRENT HIGHER EDUCATION}

As far as we know, in the current educational practice model, the practical ability is hard to be improved, so the effective reform of the practice mechanism and model is urged to be implemented, for improving the comprehensive education level, for enhancing the overall quality of university graduates ${ }^{[4-5]}$. In summary, the main problems of the current educational practice model are presented as follows ${ }^{[6-8]}$.

(1) Lack of understanding and attention, the reform of practice model is forging ahead difficultly. Under today' higher education situation in China, many people still pay attention to the scores on the paper but pay less attention to the practical ability, and both the teacher and the student are put all the energy in the lessons and examinations. And the effective evaluation mechanism of the practice is absent, who can make the practice model and the theory examination score model be obtained the equal attention, maybe it is a hard time and hard process.

(2) Lack of system construction, the guarantee of practice quality exists in name only. Although there are many kinds of educational practice products in higher education, overall, comparing to the whole learning time, the practice time is very short relatively, it is less than $5 \%$ hours in total. And the organization is random and lack of system mechanism, many colleges and universities are lack of stable practice base, the management is loose and random. Many practice subjects only need a practice report. As far as we suppose, the report maybe is just a report but without any other specific practice contents.

(3) Lack of comprehensive evaluating indicator, the practice identification cannot reflect the fact. As for the evaluation of the practice conclusion, it is lack of efficient and effective evaluating indicator and method, perhaps the practice report is the ultimate evaluating index. But the report cannot reflect the real practical ability and technical level of the students. This conclusion and evaluating method certainly can setback the enthusiasm of the students. And the practice subject score cannot reflect the fact, and also the employers are covered with a thick layer of the veil in the employment. Eventually, it results that all the people are suspicious of the practice mechanism of higher education.

(4) Lack of hardware facilities, the practice subject becomes a mere formality. Some colleges and universities invest little in the practice factories, practice environment, practice and experiment platforms. The high-tech equipments are lack. The hardware facilities are old. Eventually, it results that the practice subject becomes a mere formality, and the students involve the practice just like for tea and biscuits. The experiment education and the practice education are implemented for decades just as one day, year after year, day after day, and there is no improvement, no development. 


\section{SUGGESTIONS OF EDUCATIONAL PRACTICE REFORM AND IN APPLICATION}

According to the problem and defects of the practice model in higher education and educational system, along with process of the educational practice reform, some suggestions and proposals are proposed for the development of the educational practice reform.

(1) Strengthening the ideological understanding, establishment of new concept of education and practice. Attitude is everything, the idea is future. The awkward situation which the low efficiency of higher education practice must be changed by the reform, firstly, it needs to strengthen the organization and leadership, and enhance the ideological understanding. The position of educational practice should be corrected, and the new concept of education and practice should be built, the evaluation of practice ability should be taken as same important as the theory examination. The evaluating mechanism should put much attention to the operation skills and practice abilities. The relevant departments and colleges should increase the investment in education practice items. And the scientific research innovation ability is developed. New practice methods and effective practice subjects are researched, really make the students learn for the practice, learn with the practice.

(2) Reform of the curriculum system, cultivation of comprehensive high quality talents. Based on the practice model of embedding in the courses, make the further refine and reform, and take quality-oriented scientific management, and strict checks to ensure quality, the curriculum practice is implemented, make the students convert the theory to the practicable ability. The pertinence should be shown in the theory education, and the practical effect should be shown in the practice education. Make the practice phase of the curriculum be the pre-job training of this major course. The examination of the subject is divided into theory and practice two parts equally, really ensure the graduates can operate the related machines without new training after the subject learning. And also the occupation qualification certificate can be taken in to consideration for the qualified students. Certainly, this should coordinate to the labor and social security department, on the one hand, it stimulate the positivity for the student to participate in the practice, on the other hand, the qualification certificate is a consideration for the employers, certainly, it must be strict with strict management mechanism.

(3)Abundance of the practice models, development of efficient practice mechanism. According the survived practice models as presented above, the effective and efficient educational practice system and mechanism should be researched and specified. Make educational practice become usual and regular, and make the practice model become a comprehensive system. Each practice models are combined one by one in one organic whole with reasonable application, and develop the spirit of exploration and innovation. The education is developed with the practice, and the educational practice is developed with education. The new high quality technological and management talents are cultivated that good at many things and expert and both with socialist-minded and professionally competent. Ultimately, the effective practice model mechanism should be developed by the relevant department, and promote the integrated development for the graduates.

(4) Adjustment of the practice time, cultivation of the practice ability according to the learning time and majors. Of course, the performance and result of practice is due to the cost time and striving degree. But for the other majors, the practice time is very less as presented and analyzed as above, it just is arranged in the courses and the summer vacation, and always is shown in random. So, these students can't meet to the demands in the occupation in the preliminary stage. It is necessary to increase the practice time to a certain degree reasonably, but the whole study time in the university is limited, confronted to the so many subjects and how to coordinate the contradiction between the practice time and theory study time is a hard problem which need to be researched. In my opinion, according to the different training objectives, it can be divided into academic research students and engineering application of student. In conclusion, how to coordinate the contradiction between theory study and the practice exercise, and find the best balance of the learning and practice, the problem should be solved by the effort of the relevant department. And the ultimate objective is for the development of the social, development of the science with cultivation of the useful talents.

\section{V.CONCLUSIONS}

The education is the fundament of the country, and talent is the future of the country. The society declines high scores and low abilities. The development declines the armchair strategy. The reform of educational systems is developing, and the higher education is especially related to the fate of the country. The practice model of higher education must forge ahead along with an effective way, and pay attention to it ideologically, do it from now on. Cultivate the comprehensive high quality talents, and promote the education progress with scientific development, rapid development. That is the lucky blessing of the students, and that is the lucky blessing of the country.

\section{ACKNOWLEDGMENT}

Supported by shaanxi special funding for high level university construction project (No. 2012SXTS07) and the Yan'an University teaching reform research project(NO.YDJG12-12)

\section{REFERENCES}

[1] http://edu.sina.com.cn/j/2009-03-24/1817167949.shtml.

[2] Chen Chaowen. Discussions on the Reform of Tanching Practice for Computer Science Majors[J]. Journal of Nanning Teachers College, 2005, 22(3):75-77. 
[3] DENG Jing-sheng. The new view about reform of the method of pre-service teacher education practice under the background of new curriculum[J]. CAREER HORIZON, 2012, 8(9): 81-83.

[4] Hulman LS.. Knowledge and Teaching: Foundations of the New Reform[J]. Harvard Educational Review, 1987, 57 (1): 135-143.

[5] LIU Xu-dong. On Educational Practice Ability of Normal Students and the Reform of Education and Internship Program[J]. Contemporary Education and Culture, 2011, 3(2): 74-79.

[6] Kato, Takao. The End of Lifetime Employment in Japan: Evidence from National Surveys and Field Research [J]. Journal of the Japanese and International Economies, 2001, 4: 489-514.

[7] Tanova, C., Holtom, B.Using. Job Embeddedness Factors to Ex-plain Voluntary Turnover in 4 European Countries[J]. International Journal of Human Resource Management, 2008, 9 1553-1568.

[8] Collins, Michael. D. The effect of psychological contract fulfillment o manager turnover intentions and its role as a mediator in a casual limited-service restaurant environment[J]. International Journal of Hospitality Management, 2010, 29(4): 736-742. 